\title{
Metacarpal 1 Base
}

National Cancer Institute

\section{Source}

National Cancer Institute. Metacarpal 1 Base. NCI Thesaurus. Code C127667.

The proximal end of the first metacarpal bone. 